\section{Locating loss}

\section{Geophys. Res. Lett. 35, L17505 (2008)}

The Greenland ice sheet is melting at an unprecedented rate, but sparse sampling makes it difficult to determine the spatial distribution of loss. A high-resolution picture of glacial thinning suggests that more than $70 \%$ of ice loss in southeastern Greenland results from the melting of so-called small glaciers.

Ian Howat of Ohio State University and colleagues combined satellite measurements of surface elevation with digital elevation models of glaciers in southeastern Greenland. Assuming that elevation changes reflect changes in ice volume, they estimate that $108 \mathrm{~km}^{3}$ of ice was lost from the region each year between 2002 and 2005, consistent with independent estimates. Only $28 \%$ of this loss resulted from the melting of large glaciers such as Helheim; the remaining $72 \%$ resulted from the thinning of small glaciers.

Location-specific loss may reflect regional climate or ocean-related forcing, highlighting the need for greater observational coverage of mass loss.

\section{Rising productivity}

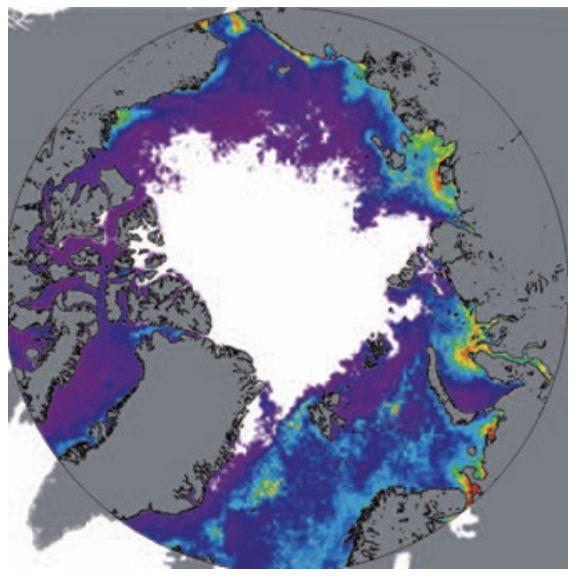

Geophys. Res. Lett. 35, L19603 (2008) Primary production in the Arctic Ocean has increased dramatically since 2002, because declining Arctic sea ice coverage has spurred phytoplankton blooms in previously barren regions of the sea. Kevin Arrigo and colleagues at Stanford University analysed satellite measurements of sea ice, sea surface temperature and chlorophyll. They found a marked rise in chlorophyll concentrations, which are an indirect measure of primary production, beginning in 2003. During 2007, production reached its highest values

\title{
The weight of the Andes
}

Earth Planet. Sci. Lett. doi:10.1016/j.epsl.2008.08.007 (2008)

The Andes Mountains rise along the South American coast where the Nazca oceanic plate subducts beneath the South American continental plate. During the past 10 million years, the weight exerted by the rapid growth of the Andes slowed the rate of convergence between the two plates.

Brendan Meade of Harvard University and Clinton Conrad of the University of Hawaii at Manoa have developed a two-dimensional numerical model to quantify the relative contribution of various forces involved in the collision of the Nazca and South American plates. They show that decreased erosion rates beginning about 10 million years ago - probably as a result of increased regional aridity - facilitated rapid growth of the Andes. The weight of the growing Andes increased friction on the plate interface, slowing the plate convergence rate by almost $50 \%$.

According to the researchers, variations in regional climate may exert an indirect, but important, influence on plate motions. since 1998, with rates of carbon-fixation $23 \%$ above the 1998-2002 baseline. The group attributes the rise in productivity to increases in the area of open water and the length of time those waters remain ice-free.

Changes in the timing and amount of surface productivity could shift the Arctic ecosystem towards larger and more diverse pelagic and benthic communities, at the expense of ice-obligate predators.

\section{Eruptions of ammonia}

Icarus doi:10.1016/j.icarus.2008.08.013 (2008)

Ammonia may periodically leak out from Titan's interior, reshaping and redefining the moon's surface. Although Titan's inner layers are thought to contain ammonia, there has been no evidence of surface ammonia.

Robert Nelson from the Jet Propulsion Laboratory, California, and colleagues studied images of Titan collected by the Cassini spacecraft from July 2004 to March 2006. They identified changes in reflectance in an area covering tens of thousands of square kilometres, suggesting a geologically active surface. The reflectance changes are best explained by the periodic deposition of ammonia frost through volcanic eruptions or geysers. Alternative explanations, such as the existence of a high-temperature region beneath the surface, do not satisfactorily explain the reflectance data.

Ammonia and methane may be interacting in Titan's surface-atmosphere system, which could provide an analogue to processes that preceded the evolution of life on the early Earth.

\section{Diversity and tectonics}

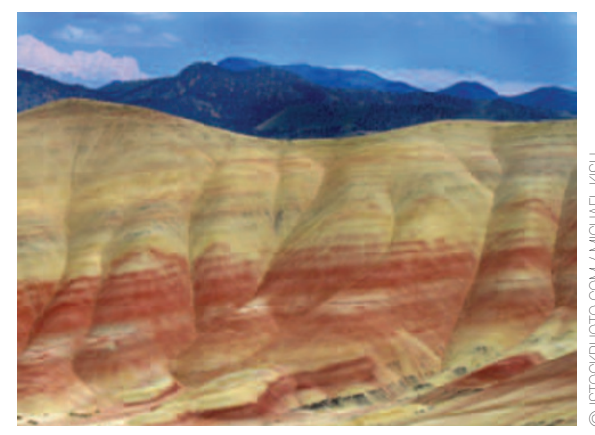

Geology36, 783-786 (2008)

Mammalian diversity in the western United States increased dramatically about 17 million years ago. This is probably related to a regional pulse of tectonic activity, which created a range of new habitats for mammals.

Matthew Kohn of Boise State University and Theodore Fremd of the John Day Fossil Beds National Monument, Oregon, re-analysed data on the occurrence and distribution of large mammal fossils from the western United States. They found a period of relatively rapid increases in diversity beginning around 17 million years ago. Existing tectonic data show increased rates of extension concurrent with this pulse in mammal radiation. The consequent development of fault-bounded mountains and basins could have created new local habitats that in turn drove the increase in biodiversity.

The researchers speculate that global climatic changes, remotely forced by the growth of the Tibetan Plateau, caused the subsequent decline in plant and animal diversity throughout the western United States. 